\title{
A crise imobiliária norte-americana: origem, perspectivas e impactos
}

\author{
Breno P. Lemos* \\ Maurício V. L. Bittencourt ${ }^{* *}$ \\ "Capitalism without financial failure \\ is not capitalism at all, \\ but a kind of socialism for the rich". \\ (Joseph Schumpeter)
}

Depois de um semestre de uso indiscriminado de pontos de exclamação em seus relatórios financeiros na tentativa de assanhar o apetite pelo risco de investidores com suas projeções, os analistas agora os substituem por incontáveis pontos de interrogação. Qual a origem do choque que os mercados financeiros atravessam? Trata-se de uma crise duradoura ou de uma turbulência passageira? Quais instituições financeiras foram alvejadas? Qual a sua circunscrição? Perguntas como estas pairam indecifráveis, sobre tais relatórios.

Entretanto, antes que fosse possível encontrar respostas, após o Federal Reserve (Fed) surpreender a todos com um corte de $0,5 \%$ na fed fund e na repo rate, a Bolsa de Valores de São Paulo (Bovespa), que outrora afundou até os 44 mil pontos, encerrou o mês de setembro na casa dos 60 mil pontos batendo, pela $40^{a}$ vez somente neste ano, sua cotação histórica38.

Fazendo uma leitura apressada, um incauto poderia afirmar que "o pior já passou", restando, agora, a tarefa de identificar as oportunidades de ganhos de arbitragem entre os ativos financeiros. Embora este seja o sentimento comum entre os analistas, seria sensato fazermos uma breve reflexão sobre o epicentro do tremor recente nos mercados financeiros mundiais: o mercado de imobiliário norte-americano. \section{americano \\ Desempenho Recente e Perspectivas do Mercado Imobiliário norte-}

A crise que recentemente mostrou sua cara afetando os mercados financeiros do mundo inteiro reflete alguns sinais de enfraquecimento do setor imobiliário norte-americano em anos recentes. Cerca de $43 \%$ dos financiamentos de casa própria em 2005 não tiveram

\footnotetext{
* Professor do Departamento de economia da PUC-PR. Economista da COPEL. Endereço eletrônico: bplemos@uol.com.br

** Professor do Departamento de Economia da UFPR. Endereço eletrônico: mbitterncourt@ufpr.br

38 Coisa semelhante ocorreu com nossa taxa de câmbio: o dólar saiu da casa dos 1,8x para os 2,1x em fins de julho, retornando àquele patamar em fins de setembro.
} 
nenhum pagamento de entrada, sendo que aproximadamente $15,2 \%$ dos compradores de imóveis em 2005 devem no mínimo $10 \%$ a mais do que seu imóvel vale atualmente, pressionando as instituições financeiras. $\mathrm{O}$ ambiente econômico também não favoreceu $\mathrm{O}$ setor nos últimos anos, pois os juros subiram de 1\% para 5,25\% de 2004 a 2006, afetando negativamente a demanda por imóveis novos. Consequentemente, US\$ 2,7 trilhões em empréstimos foram e serão reajustados em 2006 e parte de 2007 a taxas de juros mais altas.

Tradicionalmente, os financiamentos imobiliários sempre foram empréstimos de baixo risco, pois os mesmos eram garantidos (securitizados) pelas próprias propriedades. Quando os bancos estavam emprestando montantes inferiores aos valores das propriedades para aqueles que tinham bom crédito, com pagamentos de entradas razoáveis, havia a composição de um bom negócio: com baixo risco, retornos moderados previsíveis, e baixo índice de inadimplência. Mas este modelo parece ter sido esquecido, pois os próprios bancos passaram a encorajar os compradores a usar a valorização das propriedades como uma forma de garantia de pagamento das dívidas de financiamento. Mas o que aconteceria se os valores das propriedades caíssem?

De acordo com as estimativas do Departamento de Comércio dos EUA, o preço mediano de novas residências nos EUA caiu cerca de $3 \%$ desde janeiro deste ano. Além do estoque de novas residências ter sido recorde em abril, o estoque total de residências está 39 $\%$ mais alto do que no ano anterior, sendo responsável por um decréscimo nas vendas de aproximadamente $10 \%$. Ou seja, com este cenário, as dívidas mensais dos mutuários do setor imobiliário só tendem a aumentar. Desta forma, o sistema imobiliário americano se tornou um grande "cartão de crédito" e, para piorar a situação, bancos como o Washington Mutual, que demitiu mais de 2500 funcionários do seu departamento de corretores imobiliários no início de 2007, devem se tornar regra e não exceção como se previa inicialmente.

Em 2004 não havia problemas porque a taxa de juros americana era de $1 \%$. Mas posteriormente o FED elevou as taxas de juros 17 vezes seguidas, aumentando o nível de inadimplência no setor imobiliário, causando problemas à outra instituição financeira, o New Century Financial, que foi à bancarrota.

O mais interessante é que os bancos lançam estas "amortizações negativas" (pagamentos que não cobrem as cobranças de juros e que são incorporadas no montante principal da dívida) como ganhos. Para se ter uma idéia, segundo o próprio Relatório Anual do Washington Mutual, no primeiro trimestre de 2005 este banco contabilizou cerca de US\$ 25 milhões de amortizações negativas como ganhos, sendo que no mesmo período de 2006 
este montante chegou a US\$203 milhões. Ou seja, uma situação completamente insustentável para qualquer entidade financeira. As amortizações negativas aliadas a outros empréstimos de curto prazo em ativos de longo prazo não são compatíveis porque tem muita gente sem capacidade de honrar seus compromissos financeiros, ou até reticentes em fazê-lo, diante da queda relativa de valor de seu ativo frente ao tamanho do seu endividamento. Desta forma, mesmo que os pagamentos aumentem o aumento das dívidas e a queda nos valores das propriedades que vem ocorrendo recentemente vão proporcionar que o sistema entre em colapso e, quando o setor imobiliário americano entra em queda livre, o resto da economia (e boa parte das economias mundiais) vai com ele.

\section{Perspectivas para 2007/2008}

Não faz muito sentido pensar que o princípio da média reversa, como comentada no nosso artigo no volume anterior (número 9) deste boletim, poderia ocorrer de maneira suave no setor imobiliário americano após os preços de residências terem mais que dobrado no período 2000 - 2005. Aliás, o pico de preços e vendas no setor imobiliário aconteceu em agosto de 2005, mas somente agora muitos profissionais ligados a este setor parecem ter percebido isso. Na Tabela 1 pode-se notar que o ano de 2005 foi muito bom para o setor como um todo, o que não aconteceu com o ano de 2006 e nem com as perspectivas para 2007 e 2008.

Tabela 1. Alguns indicadores do setor imobiliário nos EUA para o período 2005 - 2008

\begin{tabular}{|c|c|c|c|c|}
\hline Indicadores & 2005 & 2006 & $\left.2007^{*}\right)$ & $2008^{(*)}$ \\
\hline \multicolumn{5}{|l|}{ em milhares } \\
\hline Casas prontas à venda & 7076 & 6478 & 5923 & 6269 \\
\hline Novas vendas de residências & 1283 & 1051 & 801 & 741 \\
\hline Residências em início de construção & 2068 & 1801 & 1373 & 1263 \\
\hline Casas em construção & 1716 & 1465 & 1076 & 954 \\
\hline Condomínios e apartamentos em construção & 352 & 336 & 297 & 309 \\
\hline Construção residencial ${ }^{(*)}$ & 597 & 570 & 479 & 440 \\
\hline \multicolumn{5}{|l|}{$\%$ em relação ao ano anterior } \\
\hline Casas prontas à venda & 4,4 & $-8,5$ & $-8,6$ & 5,8 \\
\hline Novas vendas de residências & 6,7 & $-18,1$ & $-23,8$ & $-7,4$ \\
\hline Residências em início de construção & 5,8 & $-12,9$ & $-23,8$ & $-8,0$ \\
\hline Casas em construção & 6,5 & $-14,6$ & $-26,5$ & $-11,4$ \\
\hline Condomínios e apartamentos em construção & 2,1 & $-4,5$ & $-11,7$ & $-4,3$ \\
\hline Construção residencial & 8,6 & $-4,6$ & $-15,9$ & $-8,0$ \\
\hline Preços de residências existentes & 12,4 & 1,0 & $-1,7$ & 2,2 \\
\hline Preços de novas residências & 9,0 & 2,3 & $-2,2$ & 1,7 \\
\hline
\end{tabular}

Fonte: National Association of Realtors (U.S. Economic Outlook, September 2007)

(*) projeção

$(* *)$ em US\$ bilhões 
De acordo com a tabela 1, 2005 foi um ano muito bom para o setor imobiliário. A construção residencial aumentou 8,6 \% e os preços de residências existentes aumentaram 12,4 $\%$, com as vendas de casas atingindo seu pico em meados de 2005 , conforme mostra a figura 1. Nas previsões para 2007 e 2008 nota-se que existe um enorme decréscimo previsto nas vendas e construções de residências, principalmente para o ano de 2007. Nas figuras 1 e 2 pode-se constatar o recente declínio das vendas e preços das casas prontas nos Estados Unidos, contrastando com o recorde de casas à venda em 2006/2007 (figuras 3 e 4).

\section{Os Impactos da Crise Imobiliária}

A queda nas vendas e nos preços dos imóveis documentada acima, de certo modo, já estava incorporada nas previsões dos analistas. Contudo, o aumento não esperado da inadimplência entre os devedores de alto risco - os quais não possuem renda estável, nem ativos para dar em garantia -, associado a um aumento na taxa de desemprego - o que aumenta ainda mais a inadimplência -, levou à aceleração da execução de hipotecas.

No momento em que as hipotecas foram firmadas, o preço dos imóveis estava inflacionado permitindo ao tomador um volume de crédito compatível a este preço. Quando o tomador entra em dificuldades, aumentam-se as execuções das hipotecas. O problema é que tais execuções coincidem com um período de desvalorização dos imóveis. Assim, as instituições financeiras assistem a uma desvalorização de suas garantias, ocasionando um descasamento entre ativos e passivos, fator que poder gerar uma situação de insolvência.

Reavivada no imaginário dos investidores institucionais, a possibilidade de insolvência de instituições financeiras causa uma crise de desconfiança que pode culminar com um clássico episódio de corrida aos bancos e fundos de investimentos para saques, o que retroalimenta a possibilidade de insolvências destas instituições. Nestes casos, os agentes se tornam avessos ao risco e "fogem" para a liquidez. A fuga para a liquidez faz o crédito ser racionado e seletivo. As dívidas deixam de ser roladas, os prazos diminuem e a exigência de garantias aumenta.

É a partir daí que a crise imobiliária pode passar a gerar externalidades negativas para os demais setores da economia. O racionamento de crédito fatalmente causará uma redução na demanda agregada da economia norte-americana e européia, arrefecendo suas taxas de crescimento, podendo ocasionar até um ambiente de recessão nestes países. A recessão leva a uma revisão para baixo no fluxo de caixa das empresas destes países, reduzindo o preço de suas ações. Entra em cena, pelo menos no plano teórico, o efeito riqueza sobre o consumo: a 
desvalorização das ações tende a reduzir a riqueza das famílias, o que faz o consumo e a demanda agregada diminuírem ainda mais.

A queda na demanda agregada diminui as importações e o volume do comércio internacional, exportando a recessão do "mundo desenvolvido" para o resto do mundo. Países que tem vínculos comerciais mais intensos com os EUA e com a União Européia sentirão com mais força o golpe, como é o caso do Brasi e do México, por exemplo.

Para evitar que a recessão tome forma nos EUA, o Fed reduziu em 0,5\% a taxa de juros básica de sua economia. A queda nos juros é um elemento que pode estimular a demanda agregada, mas tem poder limitado para retirar uma economia de uma recessão. No entanto, a resposta nos mercados acionários foi rápida, indicando que o otimismo dos investidores está em franca recuperação. A tabela abaixo mostra o desempenho recente do mercado acionário de algumas economias emergentes.

Tabela 2. Desempenho recente dos mercados acionários de países emergentes selecionados

\begin{tabular}{|c|c|c|c|c|c|}
\hline PAÍS & 2002 & 2006 & $24 / 07 / 2007$ & $16 / 08 / 2007$ & $28 / 09 / 2007$ \\
\hline$\overline{\text { BRIC }}$ & 63,48 & 283,73 & 357,81 & 297,13 & 405,93 \\
\hline EMERGENTES & 292,20 & 912,65 & $1.156,68$ & 956,86 & $1.204,90$ \\
\hline $\mathrm{AL}$ & 658,94 & $2.995,67$ & $3.967,20$ & $3.143,70$ & $4.139,64$ \\
\hline CHINA & 14,03 & 52,06 & 69,92 & 58,65 & 88,24 \\
\hline ÍNDIA & 95,94 & 390,64 & 490,39 & 432,80 & 543,08 \\
\hline ARGENTINA & 470,26 & $3.084,08$ & $3.192,12$ & $2.716,51$ & $3.284,08$ \\
\hline BRASIL & 395,36 & $2.205,43$ & $3.119,95$ & $2.354,33$ & $3.430,60$ \\
\hline CHILE & 445,49 & $1.492,42$ & $1.885,48$ & $1.623,78$ & $1.840,48$ \\
\hline MÉXICO & $1.442,84$ & $5.483,30$ & $6.492,57$ & $5.511,08$ & $6.192,37$ \\
\hline RUSSIA & 270,74 & $1.250,28$ & $1.289,36$ & $1.126,95$ & $1.310,13$ \\
\hline
\end{tabular}

Nota: O índice utilizado para apurar o desempenho dos mercados acionários é o MSCI, o qual é composto das principais ações - todas elas definidas em dólar - de um mercado ajustadas pela variação da capitalização de mercado. Este índice revela qual o desempenho do mercado acionário do país ou grupo de países. $\mathrm{O}$ BRIC é um grupo de países emergentes formado por Brasil, Rússia, China e Índia. São coniderados países emergentes: Argentina, Brasil, Chile, China, Colômbia, República Tcheca, Egito, Hungria, India, Indonésia, Israel, Jordânia, Coréia do Sul, Malaisia, México, Marrocos, Paquistão, Peru, Filipinas, Polônia, Rússia, África do Sul, Taiwan, Tailândia e Turquia. O grupo AL é composto pelos países: Argentina, Brasil, Chile, Colômbia, México e Peru.

Fonte: Elaboração própria a partir de dados disponíveis em http://www.mscibarra.com .

É possível perceber que os mercados acionários dos países emergentes já retomaram a sua tendência de alta, ultrapassando os níveis pré-crise imobiliária. Isto reflete uma expectativa de aumento do fluxo de caixa das emrpresas que compõem o mercado acionário, o que é uma evidência contra um cenário de recessão no futuro próximo. 
Será que o corte nos juros do Fed foi suficiente para afastar o fantasma da recessão na economia norte-americana? Não necessariamente. Cortar os juros num período de instabilidade financeira pode gerar uma dupla interpretação. Por um lado, o banco central dá sinais de que atuará como "emprestador em última instância" no caso de a situação no mercado financeiro piorar, fator que provoca uma maior exposição ao risco por parte dos agentes, um aumento do risco moral e do risco sistêmico. A idéia é que crises fazem parte do show e, de certo modo, são até saudáveis, uma vez que eliminam as posições exageradamente expostas aos riscos e colocam rédeas sobre a famosa alavancagem

Por outro lado, a atitude de reduzir os juros com vistas a afastar o pânico dos mercados financeiros - conhecida como princípio de Thornton - ajuda a reduzir a possibilidade de um contágio do lado financeiro para o lado real da economia. Passada a tempestade, deve-se liquidar as instituições e as posições financeiras mais frágeis para então a economia retomar a sua trajetória de normal de crescimento.

Embora os prejuízos ainda não estejam registrados nos balancetes das instituições financeiras, ao que tudo indica, a incerteza parece, aos poucos, ir cedendo espaço para a retomada da tendência de alta dos ativos dos mercados financeiros mundiais. Mas até quando durará este movimento de alta? Seu fim estaria próximo? A resposta a estas questões depende de até quando o Fed será capaz de combater crises financeiras sem gerar inflação e da disposição dos mercados em financiar os déficits gêmeos norte-americanos.

Figura 1. Relação entre vendas de novas residências e taxas de financiamentos nos EUA de 2002 a 2007

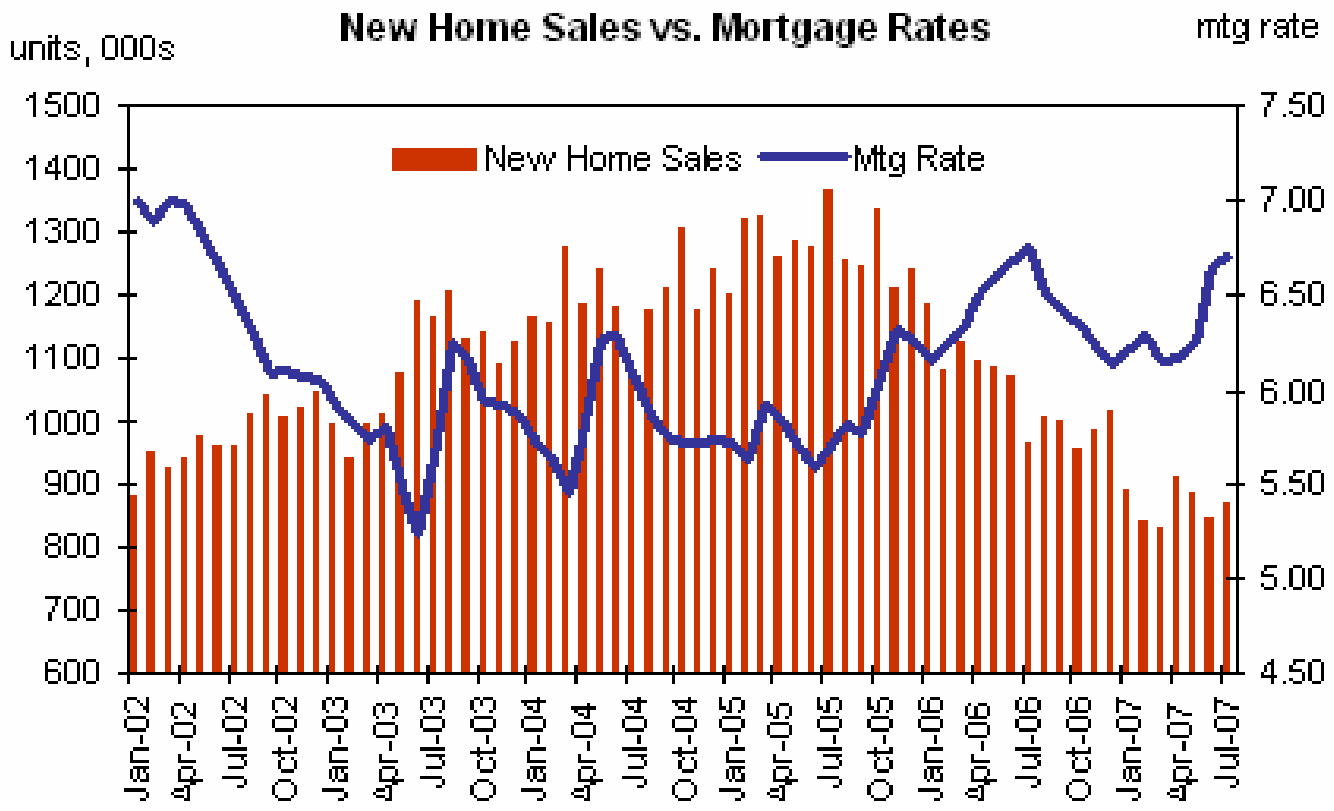

Fonte: Econoday 
Figura 2. Variação anual dos preços de casas à venda nos EUA de 2000 a 2006

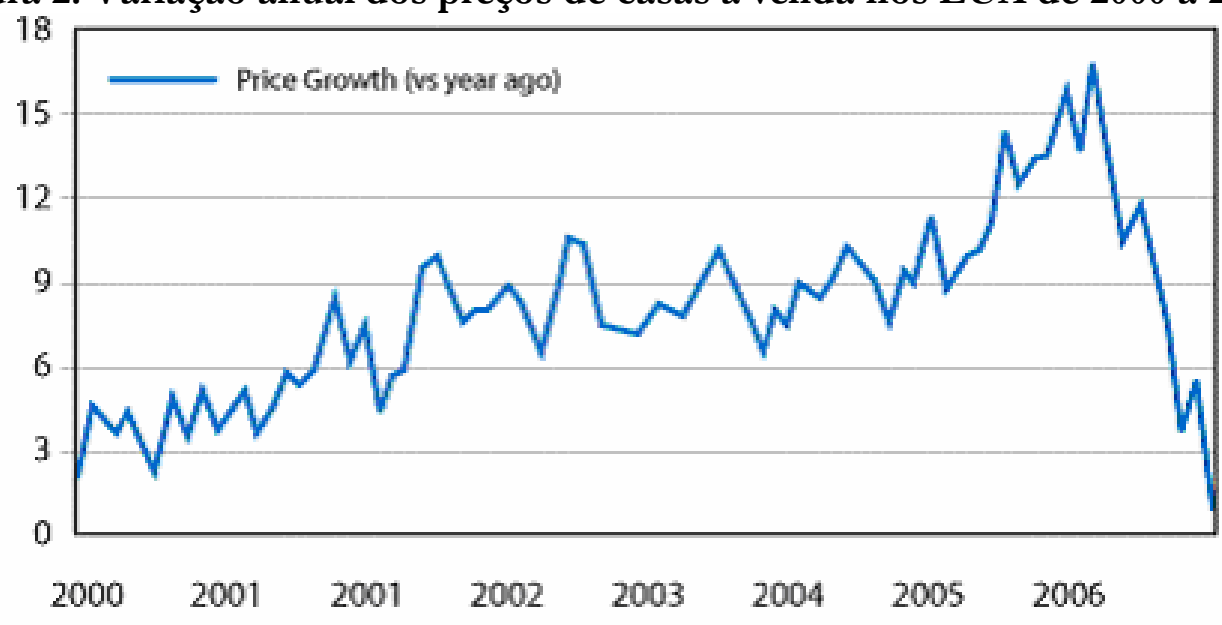

Fonte: National Association of Realtors (NAR)

Figura 3. Número de casas à venda nos EUA de 1999 a 2007

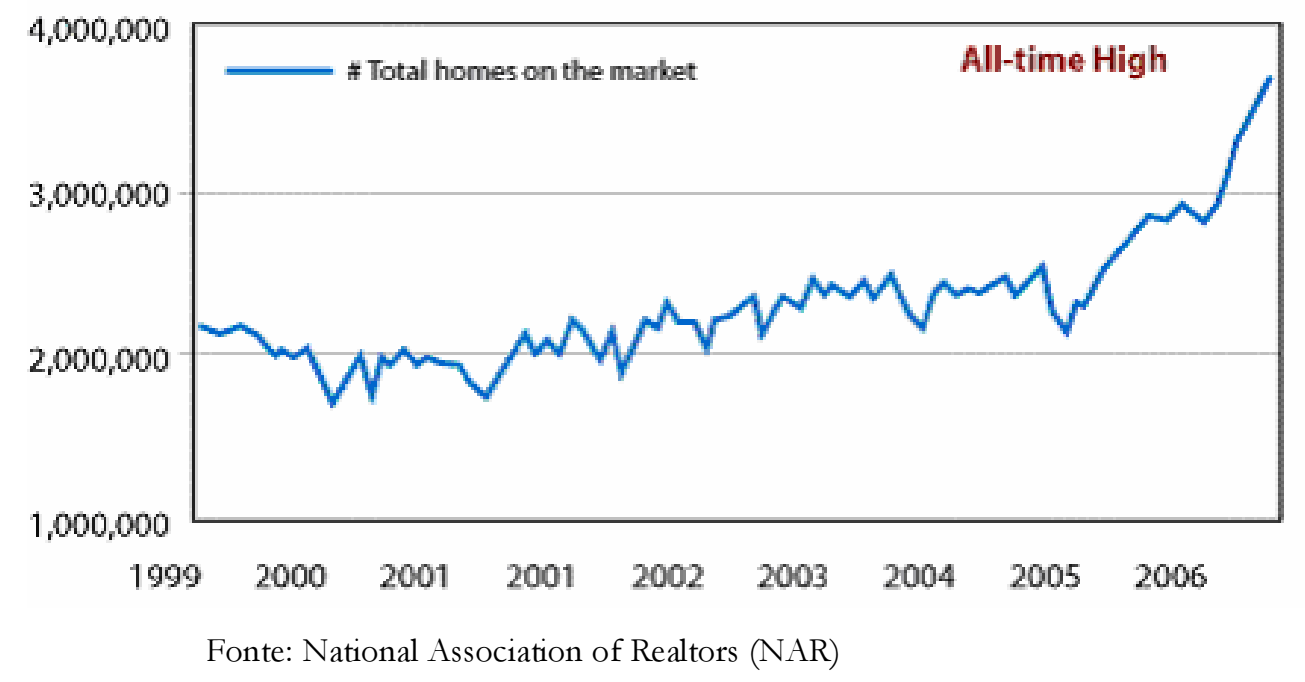


Figura 4. Vendas de casas prontas nos EUA:

Taxa anualizada - ago/06 - ago/07

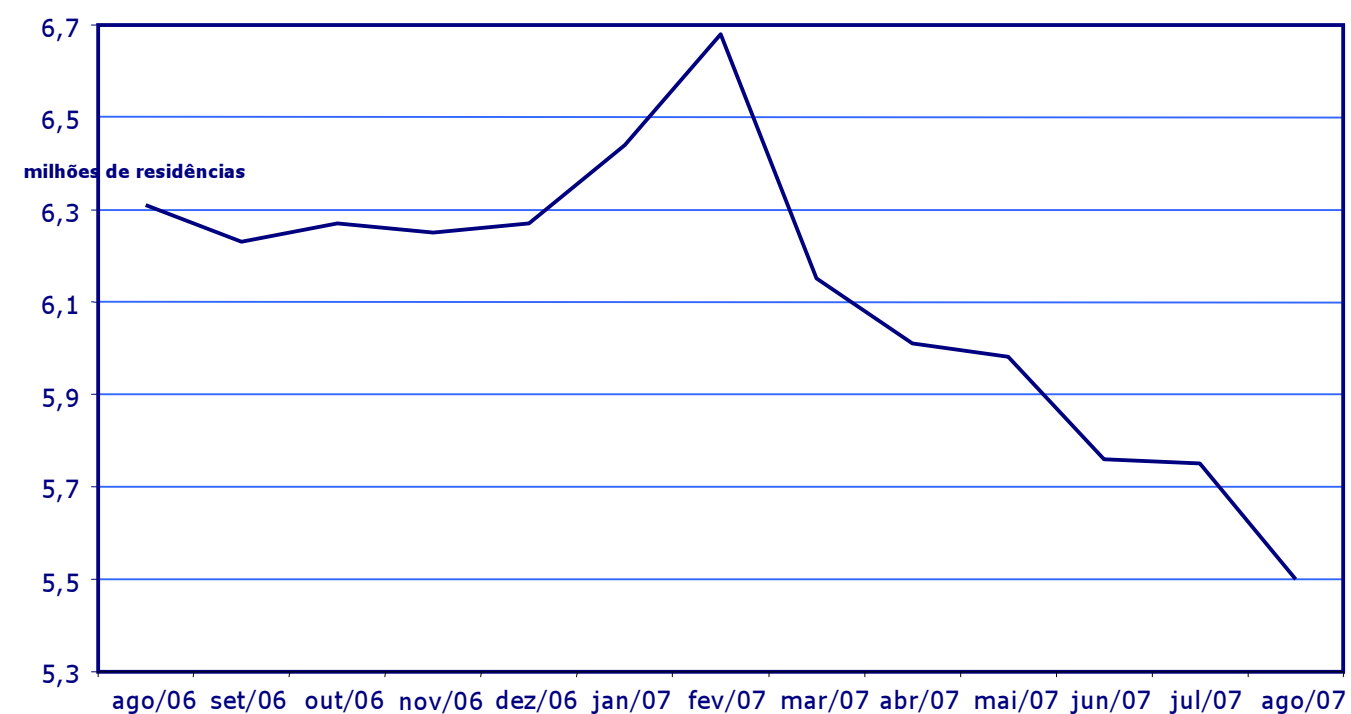

Fonte: Elaboração própria a partir de dados do National Association of Realtors 